DOE/PC/90289--T4

$\mathrm{DOE} / \mathrm{PC} / 90289--\mathrm{T} 4$

DE92 009072

\title{
Mild Coal Pretreatment to Improve
}

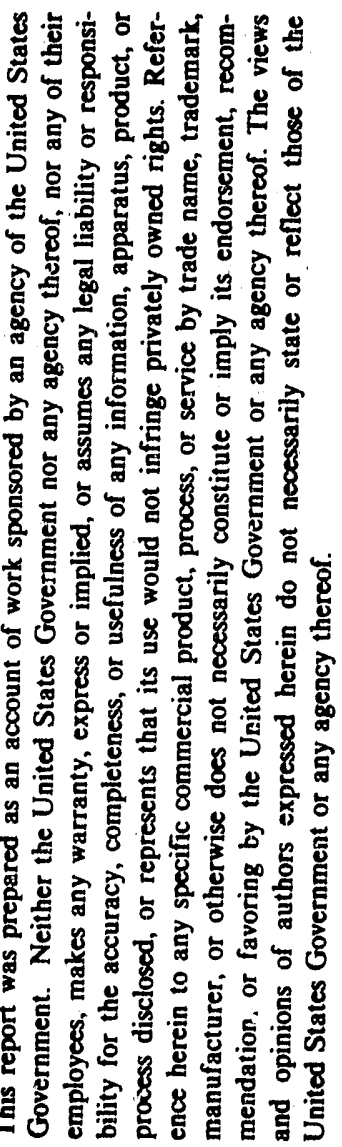

\author{
Ronald L. Miller \\ Chemical Engineering and Petroleum Refining Department
Colorado School of Mines \\ Chemical Engineering and Petroleum Refin
Colorado School of Mines \\ Golden, CO 80401 \\ Golden, CO 80401
}

Quarterly Technical Progress Report for the Period
June - August 1991

MAR 1. 199E: 


\begin{abstract}
This report describes work completed during the fourth quarter of a three year project to study the effects of mild chemical pretreatment on coal dissolution reactivity during low severity liquefaction or coal/oil coprocessing. The overall objective of this research is to elucidate changes in the chemical and physical structure of coal by pretreating with methanol or other simple organic solvent and a trace amount of hydrochloric acid and measure the influence of these changes on coal dissolution reactivity. This work is part of a larger effort to develop a new coal liquefaction or coal/oil coprocessing scheme consisting of three main process steps: 1) mild pretreatment of the feed coal to enhance dissolution reactivity and dry the coal, 2) low severity thermal dissolution of the pretreated coal to obtain a very reactive coal-derived residual material amenable to upgrading, and 3) catalytic upgrading of the residual products to distillate liquids.

Work this quarter focused on analytical characterization of untreated and pretreated Wyodak subbituminous coal and Illinois \#6 bituminous coal. ${ }^{1} \mathrm{H}$ CRAMPS NMR and ${ }^{13} \mathrm{C}$ CP/MAS NMR spectra of these coal samples indicated no observable change in hydrogen or carbon aromaticity as a result of pretreatment with methanol and hydrochloric acid. These results suggest that no significant alteration of the coal's organic phase including carbon or oxygen alkylation occurs during pretreatment.

FTIR spectra of untreated and pretreated Wyodak and Illinois \#6 coals also indicated no significant organic phase alteration with one exception. The Wyodak FTIR spectra showed the formation of carboxylic functional groups, possibly as a result of cationic bridge destruction during pretreatment. Destroying cationic $(\mathrm{Ca}, \mathrm{Mg})$ bridges may improve low severity liquefaction reactivity by reducing coordination between oxygen-containing function groups in the coal, thereby allowing better contact between coal and solvent during the initial stages of dissolution.
\end{abstract}




\section{TECHNICAL DISCUSSION}

\section{Introduction}

Much of the recent research in direct coal liquefaction seeks to develop methods for dissolving coal at lower reaction severity [often defined as temperatures below $623 \mathrm{~K}$ $\left(350^{\circ} \mathrm{C}\right)$ and pressures in the range of $\left.6.9-10.3 \mathrm{MPa}(1000-1500 \mathrm{psi})\right]$. The incentives for developing a viable low severity liquefaction process are numerous; they include:

- reduced hydrocarbon gas production resulting in reduced feed gas consumption and enhanced hydrogen utilization efficiency

- suppressed retrogression of primary coal dissolution products resulting in enhanced distillate and residuum product quality

- production of high boiling residuum which is less refractory and thus more amenable to catalytic upgrading in a conventional second-stage hydrocracker

- substitution of less expensive off-the-shelf vessels, piping, valves, pumps, etc. in place of expensive, custom-designed units

- less severe slurry handling and materials of construction problems as a result of lower operating temperatures and pressures.

The possibility of dissolving coal at low severity reaction conditions has intrigued researchers for many years. As early as 1921 , Fischer and Schrader ${ }^{1}$ reported production of an ether-soluble material by liquefying coal at $623 \mathrm{~K}\left(350^{\circ} \mathrm{C}\right)$ using carbon monoxide and water as the reducing agent. More recently, other groups including the Pittsburgh Energy Technology Center ${ }^{2-5}$, the North Dakota Energy Research Center ${ }^{6-10}$, Stanford Research Institute ${ }^{11-14}$, Carbon Resources, Inc. ${ }^{15,16}$, and the Colorado School of Mines ${ }^{17-21}$ have investigated various methods of low severity liquefaction.

Conventional coal dissolution theories have held that coal must be heated to temperatures above $673-723 \mathrm{~K}\left(400^{\circ}-450^{\circ} \mathrm{C}\right)$ to initiate thermal rupture of various labile crosslinked bonds within the three dimensional coal structure and to form free radical intermediates. Stabilization of the free radicals with hydrogen radicals results in products of lower molecular weight than the parent coal. However, work by the groups cited above and others has demonstrated that: 1) lignites, subbituminous, and bituminous coals are inherently 
more reactive than previously thought, and 2) chemical and physical coal structures can be selectively and efficiently weakened, and thus liquefaction reactivity improved, via selected chemical action rather than high temperature thermal homolysis. For example, Narayan 22 has reported that Wyodak subbituminous coal can be selectively depolymerized at room temperature and pressure in aqueous solution using periodate-borohydride and potassium crown ether reagents. Other possible depolymerization techniques include reductive and non-reductive alkylation, acylation, partial oxidation, and alkali hydrolysis. Treatments such as solvent swelling or selective demineralization can also be employed to modify the coal's physical structure.

The low severity liquefaction studies cited above have also demonstrated that while coal can be liquefied at temperatures below $623 \mathrm{~K}\left(350^{\circ} \mathrm{C}\right)$, the rate and extent of low severity dissolution is strongly dependent upon intrinsic coal reactivity. Thus, the problem of improving and optimizing low severity liquefaction processes becomes one of maximizing coal reactivity at mild reaction temperatures. Reactivity can be enhanced using: 1) dispersed homogeneous or heterogeneous catalysts 23,2 ) promoters such as basic nitrogen compound addition ${ }^{20}, 3$ ) physical pretreatment of coal 24 , or 4) chemical pretreatment of coal $^{25}$. Generally these methods all improve low severity coal liquefaction reactivity, but for various reasons (use of exotic, expensive, and sometimes hazardous chemical feedstocks, long pretreatment times, and the potential for incorporating undesirable chemical constituents into the coal), none have been seriously considered as a process step in coal liquefaction. The objective of this project has been to develop a simple, inexpensive coal pretreatment method using readily available commodity chemicals to enhance low severity liquefaction reactivity of lignites, subbituminous, and bituminous coals.

\section{Backeround}

Prior work in low severity coal liquefaction. As mentioned earlier, conventional liquefaction techniques rely on the "heat and beat" method of coal dissolution in which excessive reaction temperature, pressure, and time are used to ultimately derive a quantity 
of distillate product. Such processes are not selective towards distillable liquid production, and the resulting yield structure is far from optimal. Conventional wisdom has held that coal must be heated to temperatures above $673-723 \mathrm{~K}\left(400^{\circ}-450^{\circ} \mathrm{C}\right)$ before significant rates and extents of dissolution can be achieved. Recent advances by several research groups, most notably Stanford Research Institute (SRI), Carbon Resources, Inc., Pittsburgh Energy Technology Center (PETC), North Dakota Energy Research Center, and the Colorado School of Mines (CSM) have demonstrated that, under certain conditions, high levels of coal dissolution can be achieved at temperatures in the range of $573-623 \mathrm{~K}\left(300^{\circ}-350^{\circ} \mathrm{C}\right)$.

Ross and co-workers at SRI reported results of a low severity liquefaction study at temperatures below $673 \mathrm{~K}\left(400^{\circ} \mathrm{C}\right)$ using $\mathrm{CO} / \mathrm{H}_{2} \mathrm{O}$ but no organic solvent $11-14$. They found that $\mathrm{CO} / \mathrm{H}_{2} \mathrm{O}$ was superior to tetralin/ $/ \mathrm{H}_{2}$ as a conversion medium at low severity conditions. This result was attributed to the action of formate (an aquecus-phase water-gas shift reaction intermediate) promoting various hydrolysis reactions involving ester groups in the coal. Carbon Resources, Inc. ${ }^{15,16}$ reported THF soluble coal conversion levels of greater than $95 \mathrm{wt} \%$ (dmmf basis) at $608 \mathrm{~K}\left(335^{\circ} \mathrm{C}\right)$ and $3.45 \mathrm{MPa}(500 \mathrm{psi}) \mathrm{CO}$ pressure for low rank coals. Slightly lower conversion levels were noted with bituminous coals. Their process, known as ChemCoal, utilized phenolic solvent, alkali, and water to chemically solubilize coal via ionic attack of selected bonds (predominantly oxygen functionalities) within the coal matrix. Results of this work are especially significant since they demonstrate that essentially complete coal dissolution can be achieved at low severity conditions.

Numerous researchers at PETC have conducted low temperature liquefaction studies for many years $2-5$. Recent results using $\mathrm{CO} / \mathrm{H}_{2} \mathrm{O}$ and organic solvents suggest that higher levels of coal conversion can be achieved by using coal-derived solvent in combination with water than by using either solvent or water separately. PETC also studied low severity liquefaction using $\mathrm{H}_{2}$ gas rather than $\mathrm{CO} / \mathrm{H}_{2} \mathrm{O}$ or $\mathrm{CO} / \mathrm{H}_{2} / \mathrm{H}_{2} \mathrm{O}$ and achieved THF soluble 
coal conversion levels for Illinois \#6 coal in excess of $88 \mathrm{wt} \%$ (maf basis) at $598 \mathrm{~K}\left(325^{\circ} \mathrm{C}\right)$ reaction temperature.

Miller and Baldwin 20,21 used basic nitrogen promoters such as 1,2,3,4-tetrahydroquinoline (THQ) and dipropylamine to enhance coal dissolution rates at low severity reaction conditions. Conversions of nearly $80 \mathrm{wt} \%$ (maf basis) were obtained in single stage runs using Kentucky \#9 bituminous coal at $623 \mathrm{~K}\left(350^{\circ} \mathrm{C}\right)$ reaction temperature with nitrogen compound losses of less than $3 \mathrm{wt} \%$. Decreased reaction severity lowered the extent of nitrogen incorporation, presumably by reducing both chemical adduction and physical entrapment. Two-stage experiments were completed in which coal was dissolved at low reaction severity in the first stage using THQ as a promoter, followed by high severity catalytic upgrading of the first stage coal-derived products to distillate. Coal conversion levels and distillate yields from this process scheme were comparable to conventional twostage liquefaction (high severity thermal first stage/high severity catalytic second stage) bat with much lower hydrogen consumption and hydrocarbon gas yields. These data demonstrated the potential for developing a viable direct liquefaction process in which coal was dissolved at milder conditions than traditionally envisioned.

Prior research in chemical pretreatment of coal. Modern coal structure theories suggest that coal consists of a complex, loosely-bound three dimensional structure containing numerous strong and weak cross-linkages, hydrogen bonds, guest molecules, and other interactions among various functional groups 26 . Studies have shown that chemical treatments such as reductive and non-reductive alkylation ${ }^{27-32}$, acylation ${ }^{33}$, partial oxidation $^{34-36}$, alkali hydrolysis $37-40$, solvent swelling $41-45$, and cleavage with potassium crown ethers 22 can render coal nearly $100 \mathrm{wt} \%$ soluble in simple organic solvents such as toluene or tetrahydrofuran. This observation suggests that coal is a much less condensed and refractory material than once thought. Thus, the apparent low reactivity of many low rank and bituminous coals is, in fact, an artifact caused by the excessive thermal treatment and lack of available hydrogen during the initial stages of conventional thermal liquefaction. 
This suggests an opportunity for dissolving coal at relatively mild reaction conditions if conversion can be accomplished without irreversibly damaging the coal. We can then envision an integrated pretreatment/liquefaction process in which: 1) coal is partially depolymerized via chemical or physical pretreatment to enhance reactivity, 2) the treated coal is dissolved at low severity conditions chosen to maximize coal conversion but minimize undesirable retrogressive reactions, and, 3) the resulting residual products are catalytically hydrocracked to produce an additional yield of liquid products.

Sternberg 28 was perhaps the first investigator to demonstrate an ability to partially depolymerize subbituminous and bituminous coals at ambient reaction conditions. In this work, coal was reductively alkylated for 72-360 hours using potassium metal, naphthalene, ethyl iodide, and tetrahydrofuran (THF). Pyridine and benzene solubilities of the treated coals were found to increase with the extent of alkylation. Anthracite was found to be essentially unreactive at the reaction conditions studied. In addition to partially disrupting the coal structure by adding ethyl groups, a significant number of etheric and phenolic hydroxyl groups were also cleaved. Benzene solubilities as high as $95 \mathrm{wt} \%$ were achieved for the treated coals.

Since Sternberg's work, numerous studies of coal alkylation have been reported using reagents and catalysts such as aluminum chloride, various alkyl halides, tetrabutylammonium hydroxide, and hydrofluoric acid to name but a few 27,29-32. Once again, solvent extractabilities of the alkylated coals were found to increase sharply. Of particular interest are the results reported by Sharma, et al. 32 in which they demonstrated that bituminous coal could be alkylated using only hydrogen chloride gas and aliphatic alcohols such as n-butanol. This alkylation technique was found to increase coal extractability more than classical Friedel-Crafts alkylation carried out with aluminum chloride, isopropyl bromide, and carbon disulfide. Results of Sharma's work are particularly important, since they demonstrate the ability to alkylate coal using commodity chemicals rather than expensive reagents. 
We have concluded that new methods of enhancing coal reactivity prior to liquefaction are required to obtain satisfactory coal dissolution rates and liquid yields at low severity reaction conditions. In this study, we examined the effect of pretreating coals of various ranks using the alkyl alcohol/hydrochloric acid system reported by Sharma, et al. ${ }^{32}$ because: 1) Sharma's chemistry can potentially alkylate selected sites in the coal (primarily phenolic and carboxylic oxygen), a prime source for retrogressive reactions during coal dissolution, 2) Sharma's pretreatment method may also partially disrupt portions of the coal's mineral phase, and 3) small quantities of inexpensive chemical reagents are consumed during pretreatment.

Liquefaction reactivity of chemically pretreated coals. A search of the literature revealed two studies 40,46 in which liquefaction reactivity of pretreated coals was reported. Chow 40 used alkali hydrolysis at $373-573 \mathrm{~K}\left(100-300^{\circ} \mathrm{C}\right)$ to pretreat bituminous coal, subbituminous coal, and lignite. Results of high severity liquefaction experiments with tetralin solvent [ $683 \mathrm{~K}\left(410^{\circ} \mathrm{C}\right), 6.9 \mathrm{MPa}(1000 \mathrm{psi}) \mathrm{H}_{2}, 60 \mathrm{~min}$.] showed increased coal conversion to asphaltenes and oils. Schlosberg, et al. ${ }^{46}$ alkylated Wyodak subbituminous coal and Illinois \# 6 bituminous coal using aluminum chloride and methyl chloride at 373-423 K $\left(100-150^{\circ} \mathrm{C}\right)$ for 1 hour treatment time. The treated coal was water washed, filtered, and vacuum dried prior to liquefaction in tubing bomb reactor runs. Results from high severity liquefaction runs with tetralin $\left[700 \mathrm{~K}\left(427^{\circ} \mathrm{C}\right), 10.3 \mathrm{MPa}(1500 \mathrm{psi}) \mathrm{H}_{2}, 130\right.$ minutes $)$ showed a 10-21 wt\% increase (alkyl group-free basis) in cyclohexane soluble conversion for the alkylated coals. Neither of these studies measured liquefaction reactivity of the treated coals at lower reaction severity. Thus, any possible benefits due to increased coal reactivity brought about by the pretreatment methods employed may not have been fully realized.

\section{Experimental}

The entire suite of eight coals from the Argonne Premium Coal Sample Bank wa: used as the source of feed coals for this study, although this report focuses on chemical changes occurring during pretreatment of Wyodak subbituminous coal and Illinois \#6 bitu- 
minous coal. Ultimate analyses of the Argonne coals are listed in Table I. Additional chemical and physical properties of these coals have been reported 47 .

Pretreatment experiments were performed using a liquid phase technique we developed based on the gas phase alkylation chemistry reported by Sharma ${ }^{32}$. Coal was pretreated by suspending $5 \mathrm{~g}$ of undried coal in $40 \mathrm{~cm}^{3}$ of methanol and $0-2 \mathrm{~cm}^{3}(0-5 \mathrm{vol} \%)$ of concentrated hydrochloric acid in a $100 \mathrm{~cm}^{3}$ round bottom flask and continuously stirring the coal/methanol slurry on a magnetic stirring plate for the desired pretreatment time (usually $3 \mathrm{hrs}$.). The flask was connected to a cooling water condenser to reduce solvent losses by evaporation. Several experiments were completed in which dry nitrogen was used to blanket the coal/methanol slurry; elemental analyse; of the treated coals showed no difference in the extent of oxidation when the system vas purged with nitrogen and when it was vented to the atmosphere.

Samples were washed with $500 \mathrm{~cm}^{3}$ aliquots of methanol and centrifuged to remove excess acid and soluble mineral species from the pretreated coal. Each sample was then vacuum dried at $298 \mathrm{~K}\left(25^{\circ} \mathrm{C}\right)$ under 1.3-2.6 $\mathrm{Pa}$ (10-20 millitorr) pressure for $24 \mathrm{hrs}$. Untreated coal samples were vacuum dried at the same conditions before liquefaction. Afrer drying, all treated and untreated coal samples were stored at room temperature in a vacuum desiccator at $13.3 \mathrm{~Pa}(0.1$ torr) before analysis or liquefaction. Reactor runs were scheduled so that each coal sample was stored for less than 12 hours before use.

To study the effect of pretreatment on Wyodak and Illinois \#6 coals, portions of each pretreated coal sample were subjected to numerous chemical and physical analyses including ${ }^{1} \mathrm{H}$ and ${ }^{13} \mathrm{C}$ NMR, FTIR, Mossbauer spectroscopy, XRD, SEM and SAXS. Spectra were obtaineå using standard procedures for each type of analysis.

Liquefaction experiments were conducted in the tubing bomb reactor system. This apparatus consisted of four main components: a matched pair of $20 \mathrm{~cm}^{3}$ tubing bomb reactors, a reciprocating arm which served to agitate each reactor and its contents, a fluidized sandbath to heat the reactors, and a high pressure gas delivery system. Each reactor con- 
sisted of a body constructed from a $127 \mathrm{~mm}$ ( 5 inch) length of $12.7 \mathrm{~mm}$ (.5 inch ) O.D. 316 stainless steel tubing sealed on the bottom with a Swagelock $12.7 \mathrm{~mm}(.5 \mathrm{inch})$ nut and end plug. The top of the reactor body consisted of a Cajon VCR female gland fitting welded to the tubing body. The gland fitting was used to seal each reactor to the reciprocating arm by means of a sacrificial nickel gasket. Once linked to the arm, the reactors were connected to individual gas delivery lines and pressurized to the desired initial hydrogen pressure.

To begin an experiment, the fluidized sandbath (Tecan model SBL-20) was preheated to approximately $10 \mathrm{~K}$ above the desired reaction temperature and then raised by means of an automated hoist system to immerse the shaking reactors. The temperature and pressure of the reactor contents were continuously monitored using thermocouples and pressure transducers, respectively. At the end of the desired reaction time, the sandbath was lowered and icewater was used to quench each reactor. Reactor heatup time to $623 \mathrm{~K}\left(350^{\circ} \mathrm{C}\right)$ was achieved in approximately $80 \mathrm{sec}$. and cool down to temperatures below $473 \mathrm{~K}\left(200^{\circ} \mathrm{C}\right)$ occurred in less than $15 \mathrm{sec}$.

Coal conversion was monitored using THF extraction data corrected for the intrinsic THF solubilities of treated and untreated coals. Solubility measurements were conducted at ambient conditions and consisted of three steps: 1) sonicating the liquid products from the tubing bomb reactor (or feed coal sample) in excess THF for $10 \mathrm{~min} ., 2$ ) centrifuging the mixture at $2000 \mathrm{rpm}$ for $20 \mathrm{~min}$., and 3) decanting THF-soluble products and excess THF from the THF-insoluble residuum. This procedure was repeated at least two times until no additional THF-soluble products were recovered. Remaining THF-insolubles were dried at $373 \mathrm{~K}\left(100^{\circ} \mathrm{C}\right)$ for 24 hours to remove residual THF, weighed, and finally ashed.

Coal conversion to THF-soluble products was computed using the following formula:

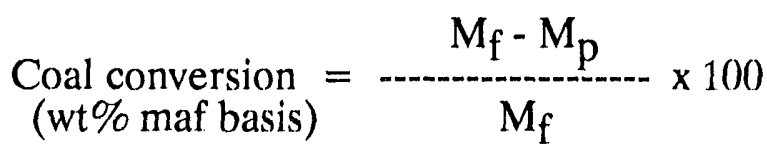


where: $\quad M_{\mathrm{f}}=$ mass of maf THF-insoluble coal charged

$$
\mathrm{M}_{\mathrm{p}}=\underset{\text { mass of maf THF-insoluble products recovered }}{\text { (corrected to satisfy the ash balance) }}
$$

This definition of coal conversion accounts for variations in the intrinsic THF solubility of treated coals. Thus reported changes in coal conversion levels can be attributed solely to inherent differences in low severity coal liquefaction reactivity.

Unless otherwise noted, low severity reaction conditions were set at $623 \mathrm{~K}\left(350^{\circ} \mathrm{C}\right)$ reaction temperature, $6.9 \mathrm{MPa}$ (1000 psig) initial cold hydrogen pressure, and $30 \mathrm{~min}$. reaction time throughout this study. Dihydrophenanthrene (DHP) was used as hydrogen donor solvent ( $2 / 1$ solvent/coal wt. ratio) in each liquefaction run.

\section{Results and Discussion}

Summary of Previous Results. Previous reports have discussed the positive effect of mild chemical pretreatment on low severity liquefaction reactivity. We have found that ambient pretreatment of eight Argonne coals using methanol and a trace amount of hydrochloric acid improves THF-soluble conversions $24.5 \mathrm{wt} \%$ (maf basis) for Wyodak subbituminous coal and $28.4 \mathrm{wt} \%$ for Beulah-Zap lignite ivith an average increase of 14.9 wt \% for the eight coals at $623 \mathrm{~K}\left(350^{\circ} \mathrm{C}\right)$ reaction temperature and $30 \mathrm{~min}$. reaction time. Similar enhancement results occurred using hexane or acetone in place of methanol. Pretreatment with methanol and $\mathrm{HCl}$ separately indicated that both reagents were necessary to achieve maximum liquefaction improvement. Acid concentration was the most important pretreatment variable studied; liquefaction reactivity increased with ircreasing acid concentration up to 2 vol\%. No appreciable effect on reactivity was observed at higher acid concentrations.

Although vapor phase alcohol/ $\mathrm{HCl}$ mixtures have been shown to partially alkylate bituminous coals, we found no indication of alkylation in our liquid phase pretreatment experiments. Possible explanations for the reactivity enhancement we observed include: 1) leaching of species such as calcium and magnesium from the coal mineral matter to reduce coordination and complexing of oxygen-containing functional groups, and 2) formation of 
chlorinated mineral species which are known coal dissolution catalysts. To begin determining if either of these two effects can account for the observed reactivity enhancement, ${ }^{1} \mathrm{H}$ CRAMPS/NMR, ${ }^{13}$ C CP/MAS NMR, FTIR, Mossbauer spectroscopy, XRD, SEM, and SAXS instrumental analyses were used to observe measurable changes in Wyodak and Illinois 6 coal samples after pretreatment. NMR and FTIR results will be presented in this report; additional data from the other analyses will be discussed in future reports.

NMR Analyses of Untreated and Treated Coals. Samples of Wyodak subbituminous and Illinois \#6 bituminous coals were treated using methanol and $\mathrm{HCl}$ at the standard pretreatment conditions $(1.5 \mathrm{vol} \% \mathrm{HCl}$ in $\mathrm{MeOH}, 3$ hours pretreatment time, 24 hours vacuum-drying at $25^{\circ} \mathrm{C}$ ). Untreated portions of each coal were also vacuum-dried for 24 hours at $25^{\circ} \mathrm{C}$. Both the untreated and treated samples were then analyzed by ${ }^{1} \mathrm{H}$ CRAMPS and ${ }^{13} \mathrm{C} \mathrm{CP} / \mathrm{MAS}$ solid state NMR techniques at the NSF Regional NMR Center, Colorado State University, Ft. Collins, Colorado. The ${ }^{1}$ H CRAMPS spectra were measured at $187 \mathrm{MHz}$ on a modified Nicolet spectrometer using a BR-24 pulse sequence.

Results from the ${ }^{1} \mathrm{H}$ CRAMPS measurements are shown in Figures 1-4. For each coal, spectra for the untreated and treated samples are nearly identical. Values of coal hydrogen aromaticity computed from the spectra are also unaffected by pretreatment. Thus, mild chemical pretreatment using methanol and $\mathrm{HCl}$ does not appear to alter the bulk organic structure of either Wyodak or Illinois \#6 coal.

Results from the ${ }^{13} \mathrm{C} \mathrm{CP} / \mathrm{MAS}$ measurements are shown in Figures 5-8. Once again, no significant differences are noted in the untreated and treated spectra for each coal. Carbon aromaticity values computed from these spectra do not vary as a result of pretreatment. These spectra also indicate that no changes occur in the bulk organic structure of either coal studied.

FTIR Analyses of Untreated and Treated Coals. The infrared spectra of untreated and treated Wyodak and Illinois \#6 coals were measured using a Digilab FTS-40 FTIR system. Samples were prepared as $\mathrm{NaCl}$ pellets and scanned 500 times to record each 
absorbance spectrum. The infrared spectra are shown in Figures 9 and 10 for Wyodak coal and Illinois \#6 coal, respectively. No evidence of coal alkylation is present in either set of spectra. However, the emergence of a significant peak near $1700 \mathrm{~cm}^{-1}$ in the treated Wyodak coal spectrum suggests the formation of carboxylic functional groups, possibly resulting from destruction of cationic bridges involving calcium and magnesium cations as

proposed by Mochida, et al. 48 These structures are not present in higher rank coals, and no indicatinn of carboxylic acid formation exists in the Illinois \#6 spectra. The FTIR results suggest that, with the possible exception of cationic bridge destruction, no significant alterations of either coal's organic structure occur during mild coal pretreatment with methanol and $\mathrm{HCl}$.

\section{Conclusions}

In previous reports, we have presented data which demonstrate the beneficial use of ambient, liquid phase coal pretreatment using methanol/ $\mathrm{HCl}$ to significantly improve low severity liquefaction reactivity. The pretreatment enhances reactivity for coals over a wide range of rank, but works best with lignite and subbituminous coals. Other organic solvents such as hexane and acetone can be used to replace methanol with equally effective results. Of the pretreatment parameters studied, only acid concentration affects liquefaction reactivity; r`sults are not influenced by changes in pretreatment times between 3 and $24 \mathrm{hrs}$. and pretreatment temperatures between $25^{\circ}$ and $55^{\circ} \mathrm{C}$.

NMR and FTIR analyses of untreated and pretreated Wyodak and Illinois \#6 coals suggest that, with the possible exception of cationic bridge destruction, no significant organic alterations occur in either coal during $\mathrm{MeOH} / \mathrm{HCl}$ pretreatment. This results indicates that chemical and/or physical changes in the coal's inorganic phase must be responsible for the observed increases in pretreated coal low severity liquefaction reactivity.

\section{Work in Progress}

During the coming quarter, work will continue to characterize the physical and chemical changes taking place in coal during mild chemical pretreatment with methanol and $\mathrm{HCl}$. 
Because few obvious changes are occurring in the coal's organic phase, we will now begin concentrating on analyzing changes in the inorganic phase during pretreatment. XRD, SEM, Mossbauer spectroscopy, and SAXS techniques will be used in this portion of the project. Results from this work will be presented beginning in the next quarterly technical progress report.

\section{LITERATURE CITED}

1. Fischer, F. and Schrader, H. Brennstoff-Chem. 1921, 2, 257

2. Appell, H.R., Moroni, E.C. and Miller, R.D. Am. Chem. Soc. Div. Fuel Chem. Prepr. $1975, \underline{20}(1), 58$

3. Fu, Y.C. and Illig, E.G. Ind. Eng. Chem. Proc. Des. Dev. 1976, 15, 392

4. Bockrath, B.C., Illig, E.G., Finseth, D.H. and Sprecher, R.F. Am. Chem. Soc. Div. Fuel Chem. Prepr, 1984, 29 (5), 76

5. Blaustein, B.D., Bockrath, B.C., Davis, H.M., Friedman, S., Illig, E.G. and Mikita, M.A. Am. Chem. Soc. Div. Fuel Chem. Prepr. 1985, 30 (2), 359

6. Severson, D.E., Souby, A.M. and Baker, G.G. Am. Chem. Soc. Div. Fuel Chem. Prepr. $1977, \underline{22}(6), 161$

7. Severson, D.E., Souby, A.M. and Owens, T.C. Energy Sources 1982, $\underline{6}, 173$

8. Sondreal, E.A., Willson, W.G. and Stenberg, V.I. Fuel 1982, 61,925

9. Knudson, C.L., Willson, W.G. and Baker, G.G. Am. Chem. Soc. Div Fuel Chem. Prepr. $1981, \underline{26}(1), 132$

10. Farnam, S.A., Wolfson, A.C., Miller, D.J., Gaides, G.E. and Merrick, D.D. Am. Chem. Soc Div. Fuel Chem. Prepr. 1985, $30(2), 354$

11. Ross, D.S., Blessing, J.E., Nguyen, Q.C. and Hum, G.P. Fuel 1984, $\underline{63}, 1206$

12. Ross, D.S., Hum, G.P., Miin, T.C. and Green, T.K. Am. Chem. Soc. Div. Fuel Chem. Prepr. 1985, 30(3), 94

13. Ross, D.S. 'Exploratory Study of Coal Conversion Chemnistry,' Final Report for DOE Contract No. DE-AC22-81PC40785, December 1984.

14. Ross, D.S., Hum, G.P. and Green, T.K. Am. Chem. Soc. Div. Fuel Chem. Prepr. $1985, \underline{30}(4), 339$

15. Porter, C.R. and Kaesz, H.D. 'The ChemCoal Process for the Chemical Transformation of Low Rank Coal,' in Proceedings of the Thirteenth Biennial Lignite Symposium, Bismarck, North Dakota, May 21-23, 1985, pp. 357-365 
16. Porter, C.R. and Kaesz, H.D. Coal Processing Technology, Amer. Inst. Chem. Engr. 1981, vol. VII, pp. 135-140

17. Miller, R.L. and Baldwin, R.M. Am. Chem. Soc. Div. Fuel Chem. Prepr. 1986, 31(1), 301

18. Miller, R.L. and Baldwin, R.M. Am. Chem. Soc. Div. Fuel Chem. Prepr. 1986, 31(4), 152

19. Miller, R.L. 'Liquefaction Co-Processing: A Study of Critical Variables,' Electric Power Research Institute Final Report for Project No. 2383-1, October 1987

20. Miller, R.L., Giacomelli, G.F., McYugh, K.J. and Baldwin, R.M. Energy \& Fuels 1989, $\underline{3}, 127$

21. Miller, R.L., Baldwin, R.M. and Kennar, D.R. Am. Chem. Soc. Div. Fuel Chem. Prepr. $1990, \underline{35}(1), 9$

22. Narayan, R. and Huang, S. 'Structure and Reactivity of a Subbituminous Coal,' in Proceedings of the Tenth Electric Power Research Institute Contractors' Conference on Clean Liquid and Solid Fuels, Palo Alto, CA, A.pril 23-25, 1985, pp. 7-1 to 7-25

23. Herrick, D.E., Tierney, J.W., Huffman, G.P. and Wender, I. Am. Chem. Soc. Div. Fuel Chem. Prepr. 1989, 34 (3), 866

24. Nguanprasert, O. 'Use of Mild Chemical Pretreatment to Enhance Coal Reactivity,' Ph.D. Dissertation no. T-4053, Colorado School of Mines, Golden, Colorado, 1991

25. Baldwin, R.M., Nguanprasert, O., Kennar, D.R. and Miller, R.L. Am. Chem. Soc. Div. Fuel Chem. Prepr. 1990, 35(1), 70

26. Given, P.H., Marzec, A., Banton, W.A., Lynch, L.J. and Gerstein, B.C. Fuel 1986, $\underline{65}$, 155

27. Wender, i., Herdy, L.A., Heuworth, M.B. and Dryden, I.G.C. 'Chemical Reactions and the Constitution of Coal,' in Chemistry of Coal Utilization, Second Supp. Vol., M.A. Elliott, ed., John Wiley, 1981.

28. Sternberg, H. and Delle Donne, C.L. Fuel 1974, $\underline{5}$, 172

29. Larsen, J.W. and Kuemmerle, E.W. Fuel 1976, 55, 162

30. Flores, R.A., Geigel, M.A. and Mayo, F.R. Fuel 1978, 57, 697

31. Liotta, R. Fuel 1979, 58,724

32. Sharma, D.K., Sarkar, M.K. and Mirza, Z.B. Fuel 1985, 64 , 449

33. Hodek, W. and Kolling, G. Fuel 1973, $\underline{52}, 220$

34. Hessley, R.K. 'Co-Oxidative Depolymerization of Coal,' Final Report for Electric Power Research Institute Project No. 2383-2, June 1985.

35. Deno, N.C., Curry, K.W., Greigger, B.A., Jones, A.D., Rakitsky, W.G., Smith, K.A., Wagner, K. and Minard, R.D. Fuel 1980, 59,694 
36. Deno, N.C., Jones, A.D., Koch, C.C., Minard, R.D., Potter, T., Sherrard, R.S., Stroh, J.G. and Yevak, R.J. Fuel 1982, 61, 490

37. Mirza, Z.B., Sarkar, M.K. and Sharma, D.K. Fuel Proc. Tech. 1984, 9 , 149

38. Shreve, R.N. and Brink, J.A. Chemical Process Industries, 4th ed., chapter 33, McGrawHill, 1977

39. Fischer, P.E., Ouyang, W. and Shah, R. 'Low Temperature Aqueous Alkaline Liquefaction of 'Texas Lignite,' in Proceedings of the Thirteenth Biennial Lignite Symposium, Grand Forks, North Dakota, May 21-23, 1985, pp. 421-434

40. Chow, C.K. Fuel 1983, 62, 317

41. Sanada, Y. and Honda, H. Fuel 1986, $\underline{6}, 295$

42. Gorbaty, M. L. 'Challenges in Fossil Fuel Chemistry," in Magnetic Resonance, Advanced Topics and Applications to Fossil Energy, L. Petrakis and J.P. Fraissard, eds., D. Reidel: Dordrecht, The Netherlands, 1984

43. Marzec, A. Fuel Proc. Tech. 1979, 2, 35

44. Bockrath, B.C., Illig, E.G. and Wassell-Bridger, W.D. Energy and Fuels 1987, 1, 226

45. Larsen, J.W. and Kovac, J. 'Polymer Structure of Bituminous Coals,' in Organic Chemistry of Coals,' Am. Chem. Soc. Symposium Series 71, 1978

46. Schlosberg, R.H., Neavel, R.C., Maa, P.S. and Gorbaty, M.L. Fuel 1980, 59, 45

47. Vorres, K.S. Users Handbook for the Argonne Premium Coal Sample Program, Argonne National Laboratory, Argonne, Illinois, October 1989

48. Mochida, I., Shimohara, T., Korai, Y., Fujitsu, H. and Takeshita, K. Fuel, 1983, 62, 659 
Table I

Ultimate Analysis of Feed Coals

\begin{tabular}{lrccc} 
Wt\% Dry Basis & Wyodak & Beulah-Zap & Illinois \#6 & Pittsburgh \#8 \\
Carbon & 68.4 & 65.9 & 65.7 & 75.5 \\
Hydrogen & 4.9 & 4.4 & 4.2 & 4.8 \\
Nitrogen & 1.0 & 1.0 & 1.2 & 1.5 \\
Sulfur & 0.6 & 0.8 & 4.8 & 2.2 \\
Oxygen & 16.3 & 18.2 & 8.6 & 6.7 \\
Ash & 8.8 & 9.7 & 15.5 & 9.3 \\
Coal Rank & Subbit. & Lignite & HVB & HVB \\
Symbol & Wy & BZ & Ill & Pit \\
\hline
\end{tabular}

Table I (cont.)

Ultimate Analysis of Feed Coals

\begin{tabular}{lcccc} 
Wt\% Dry Basis & $\begin{array}{c}\text { Blind } \\
\text { Canyon }\end{array}$ & $\begin{array}{c}\text { Lewiston- } \\
\text { Stockton }\end{array}$ & $\begin{array}{c}\text { Upper } \\
\text { Freeport }\end{array}$ & Pocahontas \\
Carbon & 76.9 & 66.2 & 74.2 & 86.7 \\
Hydrogen & 5.5 & 4.2 & 4.1 & 4.2 \\
Nitrogen & 1.5 & 1.3 & 1.4 & 1.3 \\
Sulfur & 0.6 & 0.7 & 2.3 & 0.7 \\
Oxygen & 10.8 & 7.8 & 4.8 & 2.3 \\
Ash & 4.7 & 19.8 & 13.2 & 4.8 \\
Coal Rank & HVB & HVB & MVB & LVB \\
Symbol & BC & LS & UF & POC \\
\hline & & & &
\end{tabular}




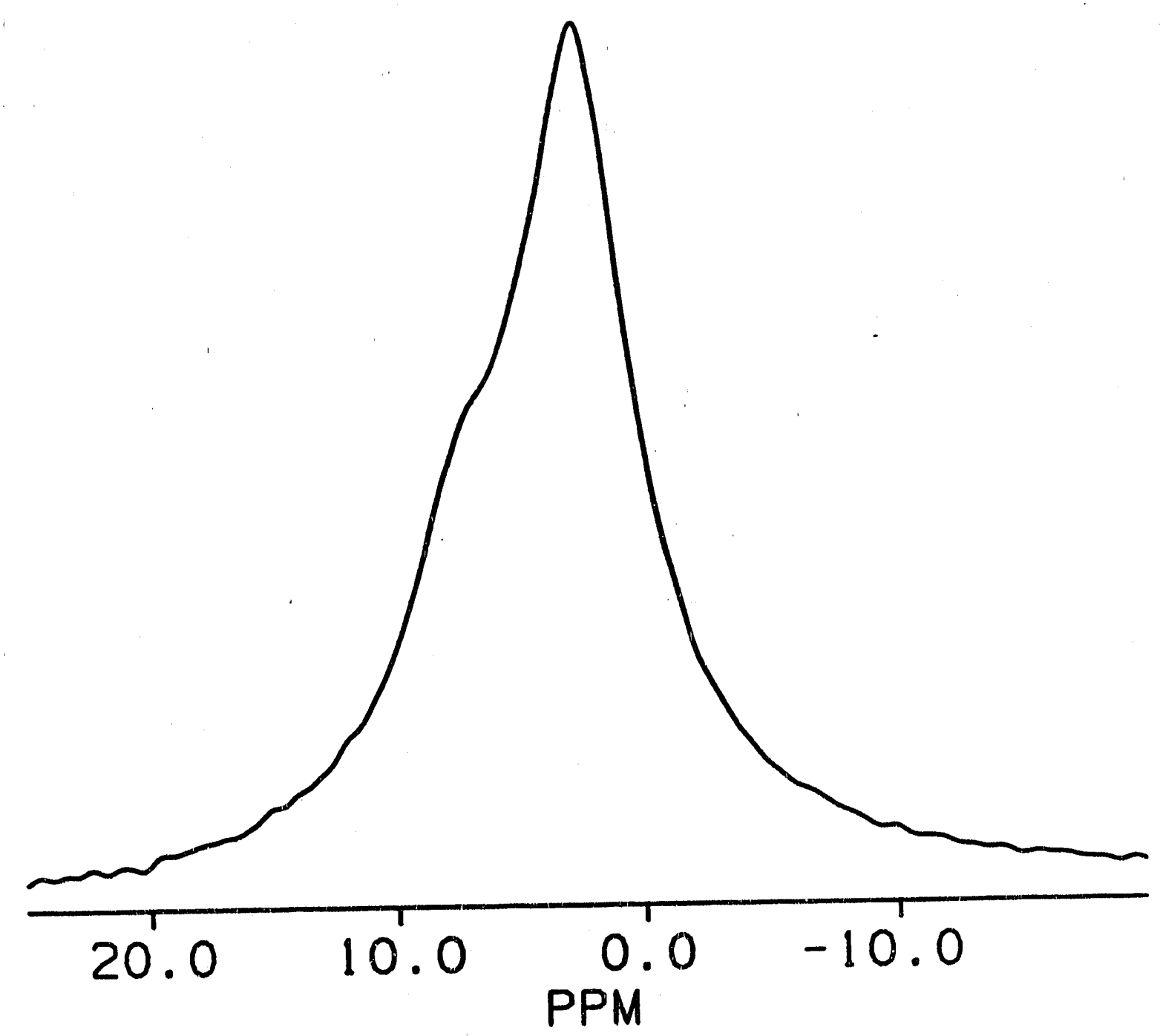

Figure 1 - ${ }^{1}$ H CRAMPS NMR Spectrum of Untreated Wyodak Coal

$-17-$ 


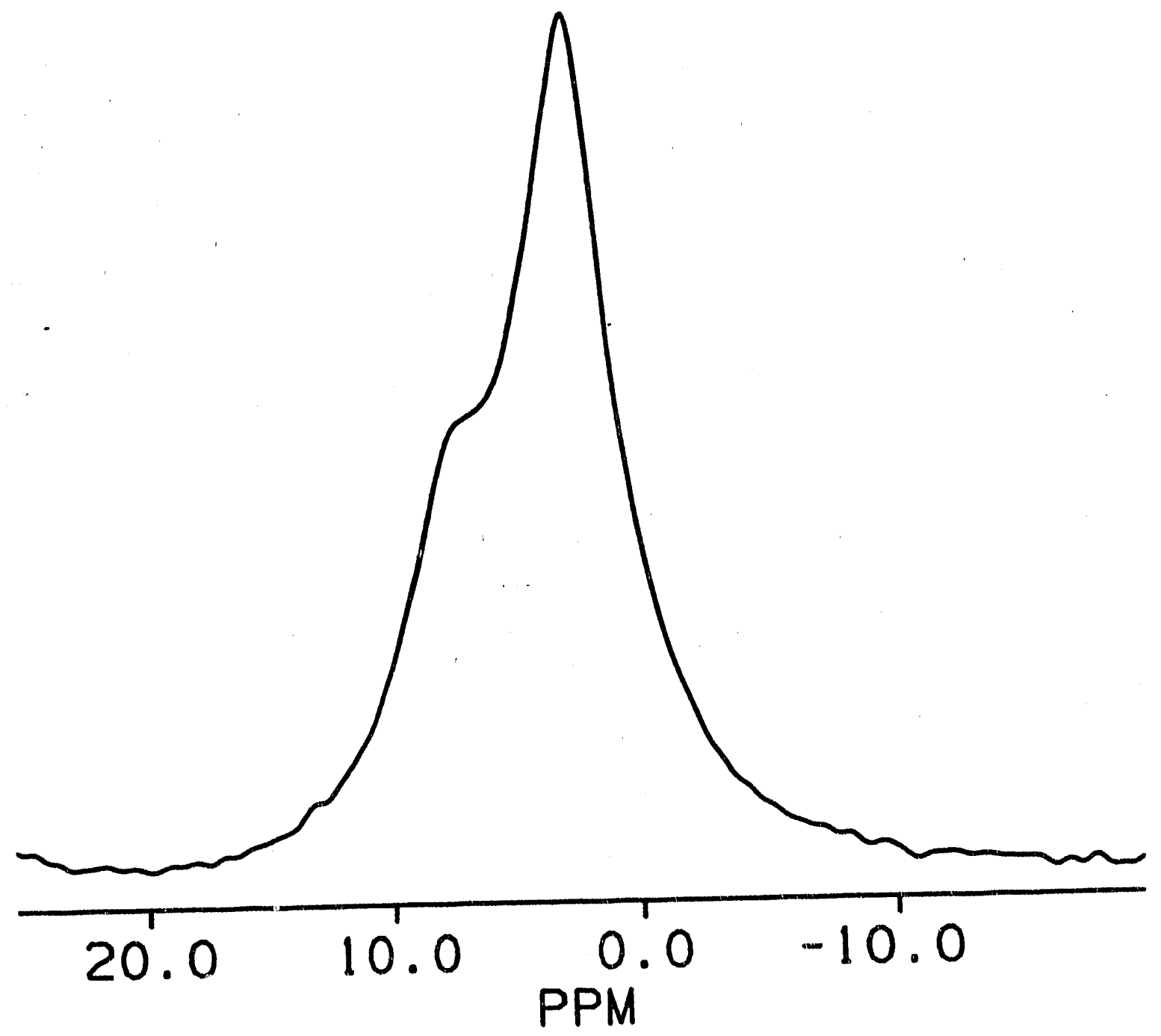

Figure 2 - ${ }^{1}$ H CRAMPS NMR Spectrum of Treated Wyodak Coal 


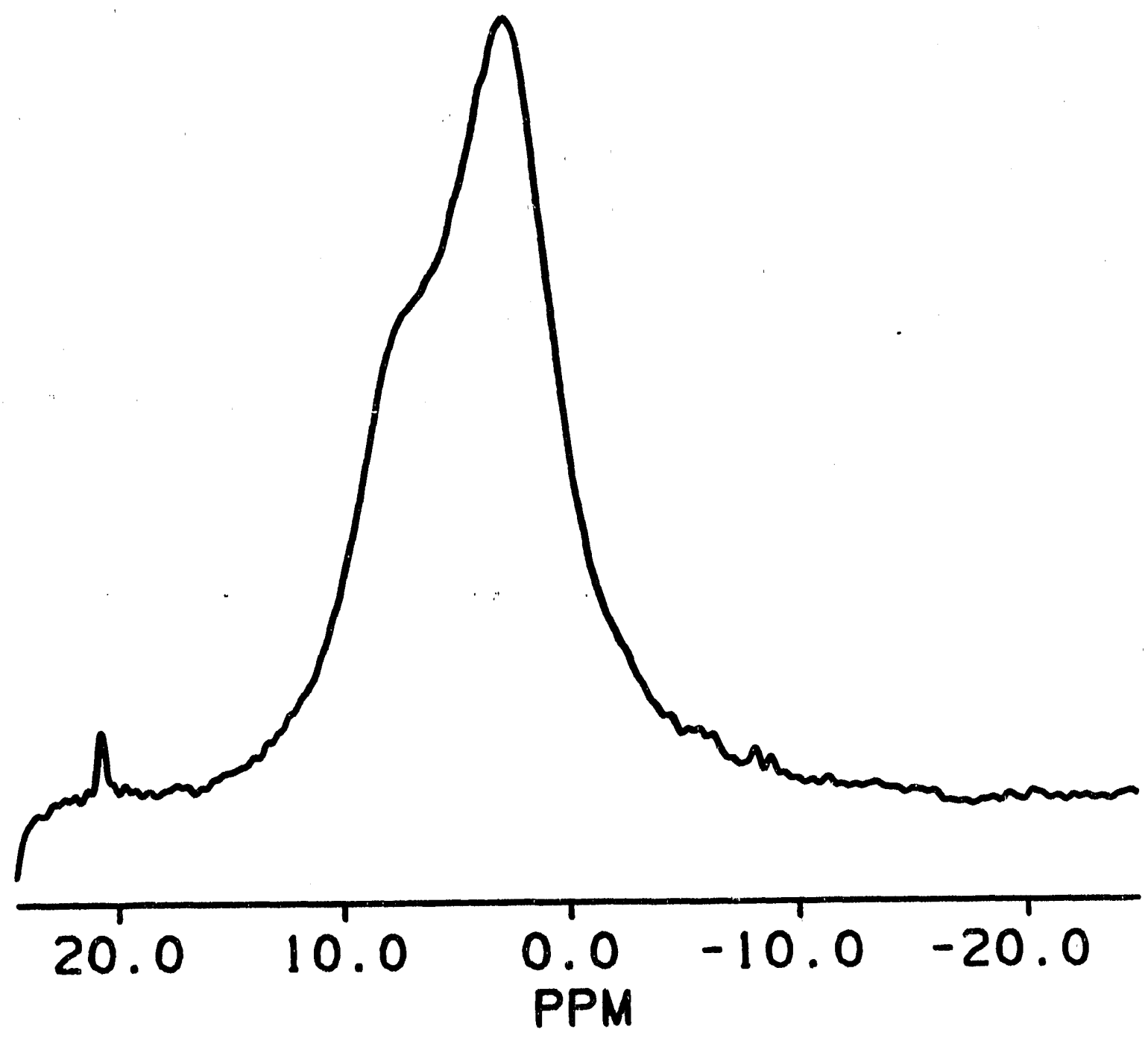

Figure $3-{ }^{1}$ H CRAMPS NMR Spectrum of Untreated Illinois \#6 Coal 


$$
\underline{n}
$$




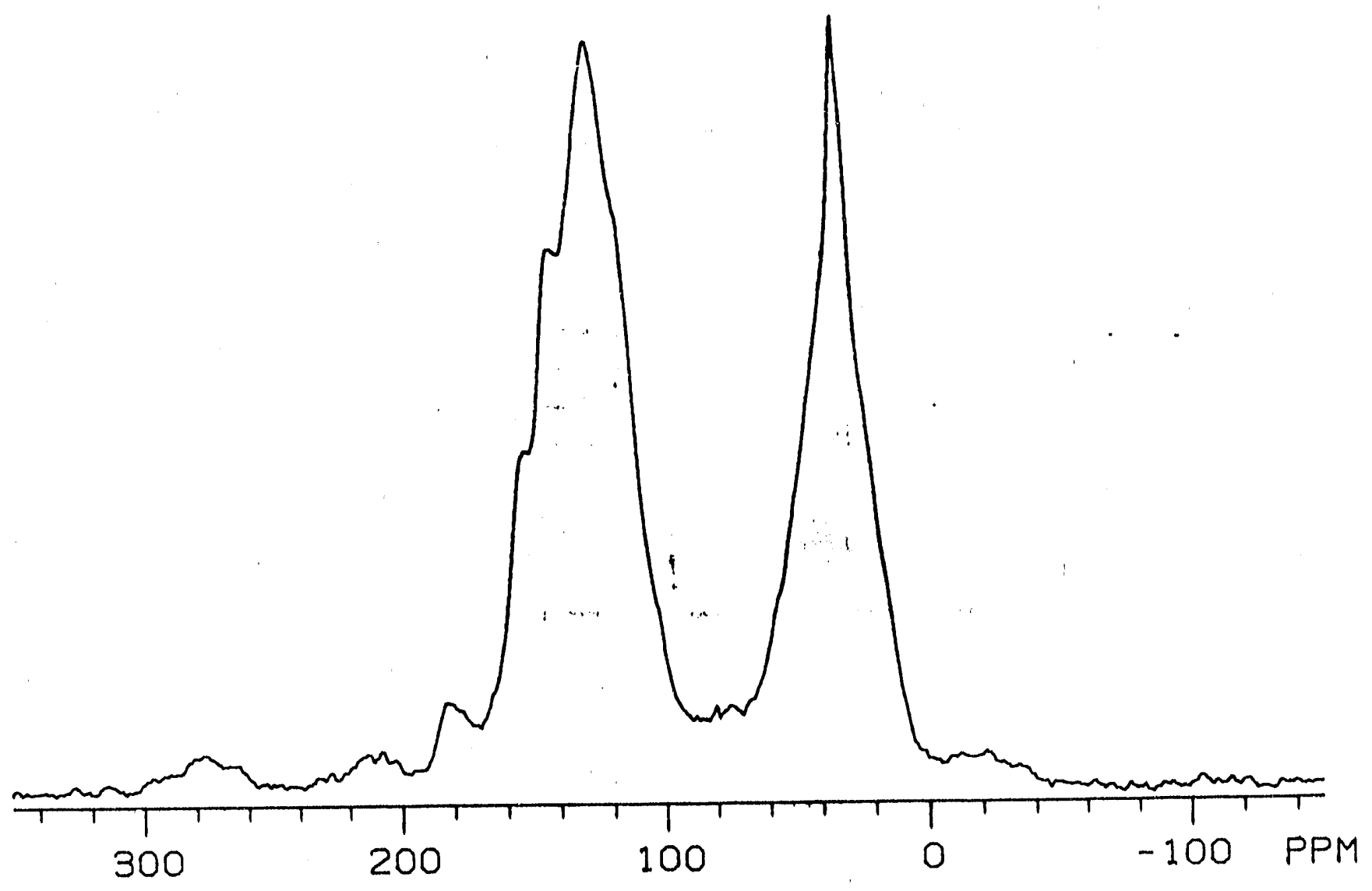

Figure $5-{ }^{13} \mathrm{C} C \mathrm{CP} / \mathrm{MAS}$ NMR Spectrum of Untreated Wyodak Coal 


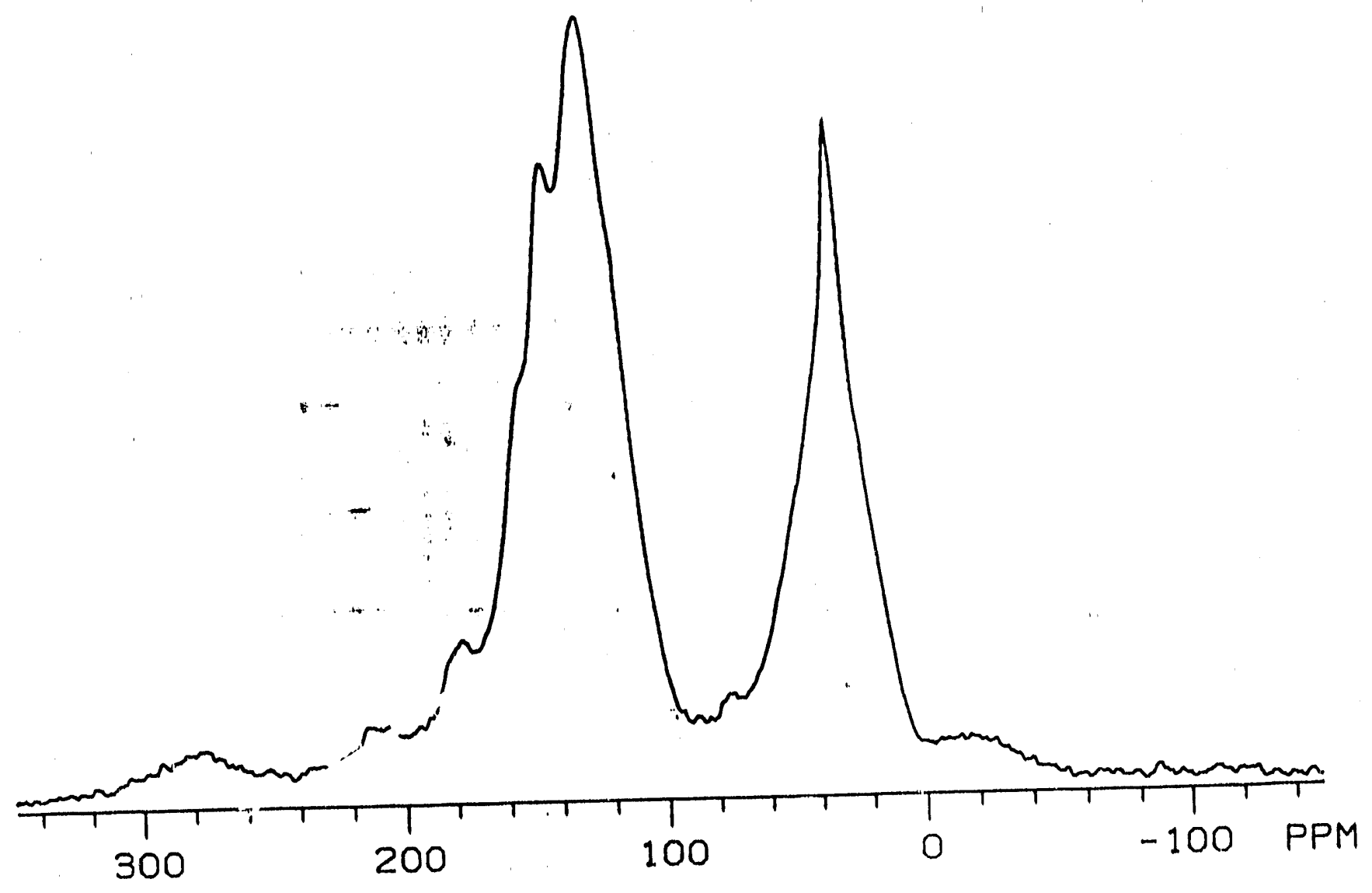

Figure $6-{ }^{13} \mathrm{C} \mathrm{CP} / \mathrm{MAS}$ NMR Spectrum of Treated Wyodak Coal 


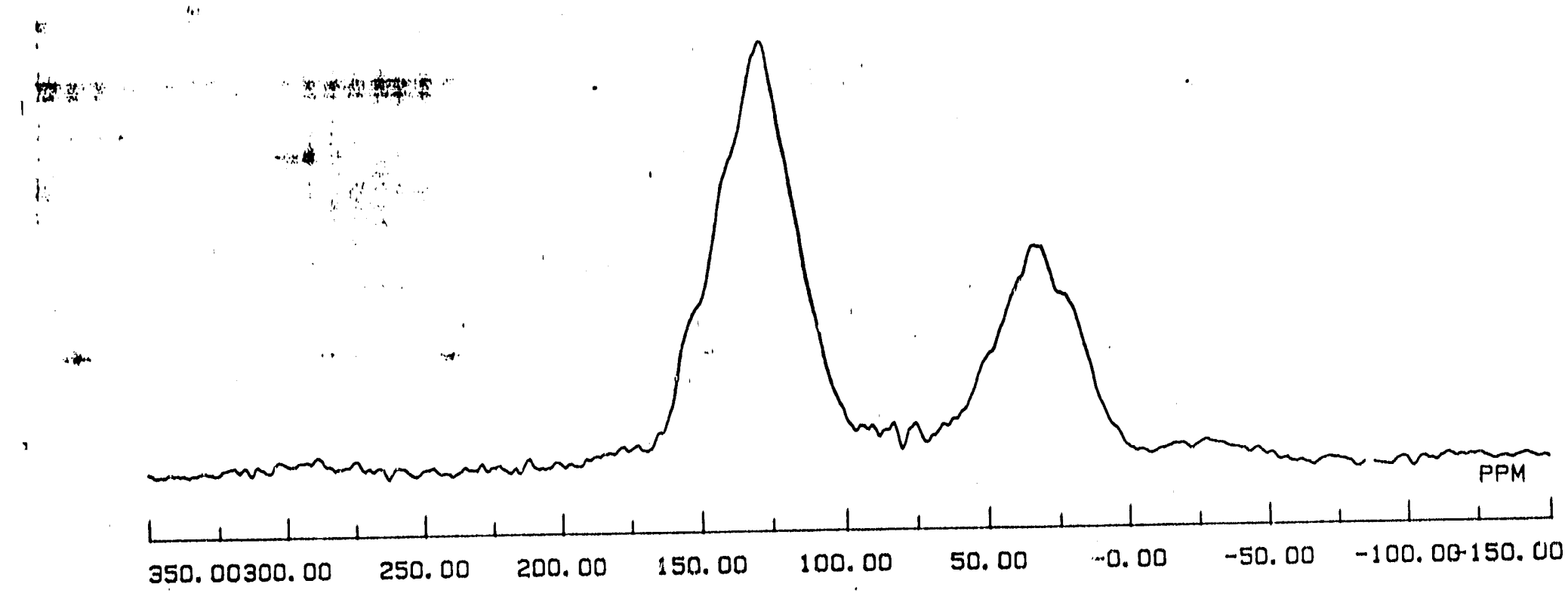

Figure 7 - ${ }^{13} \mathrm{C} \mathrm{CP} / \mathrm{MAS}$ NMR Spectrum of Untreated Illinois \# 6 Coal 


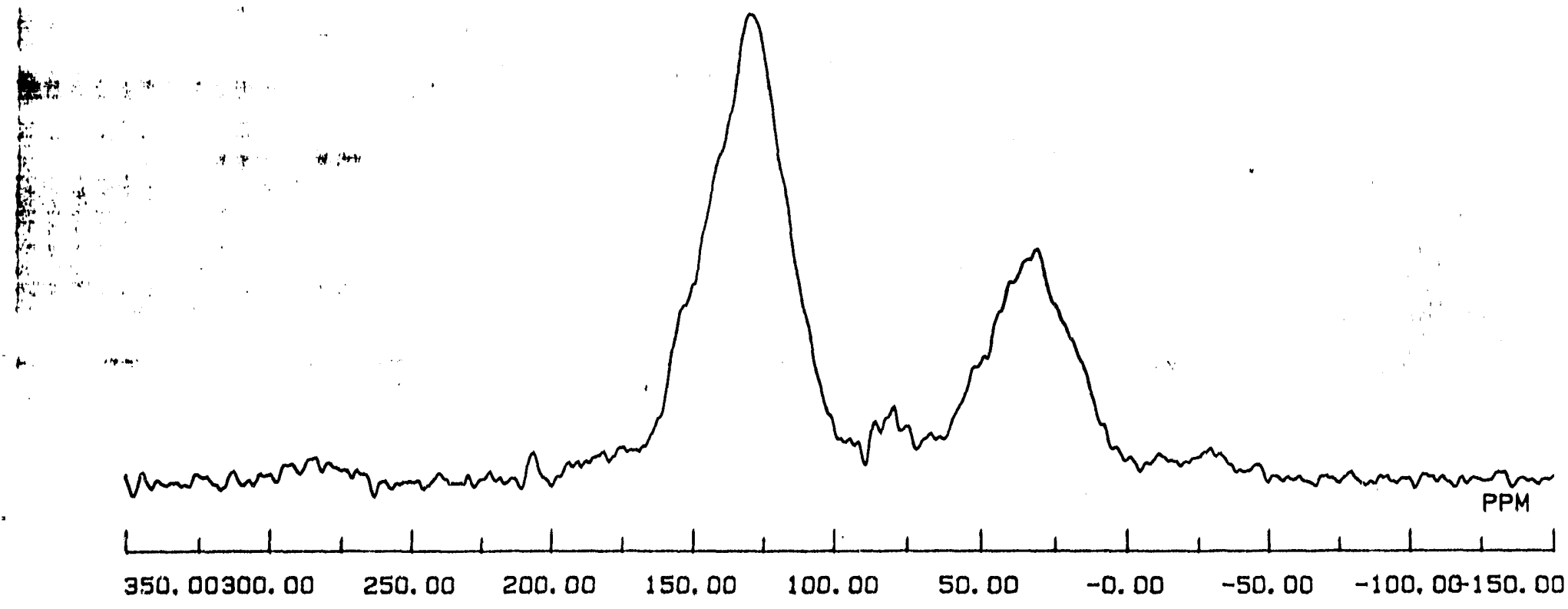

Figure $8-{ }^{13} \mathrm{C} \mathrm{CP} / \mathrm{MAS}$ NMR Spectrum of Treated Illinois \#6 Coal 


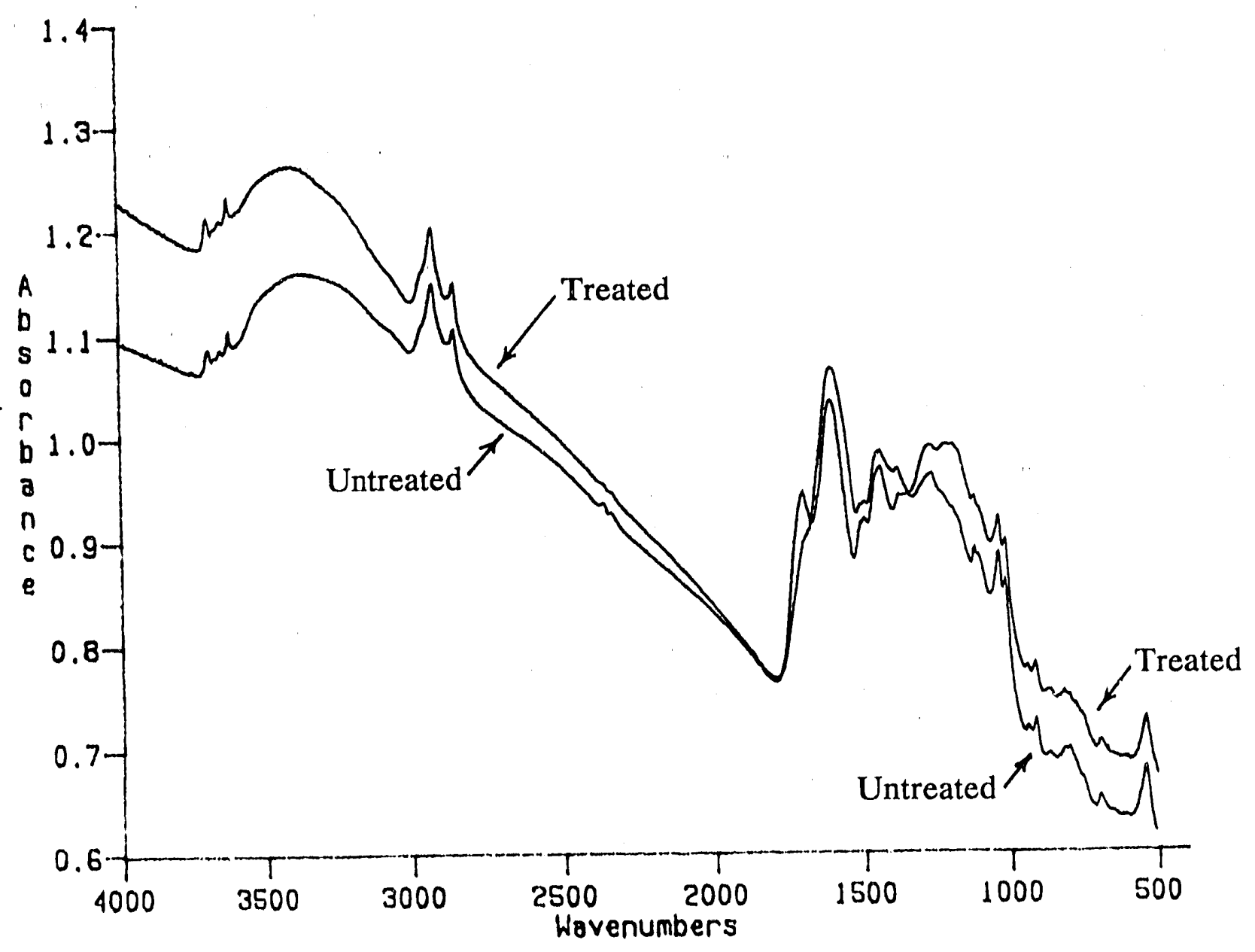

Figure 9 - FTIR Spectrum of Untreated and Treated Wyodak Coal 


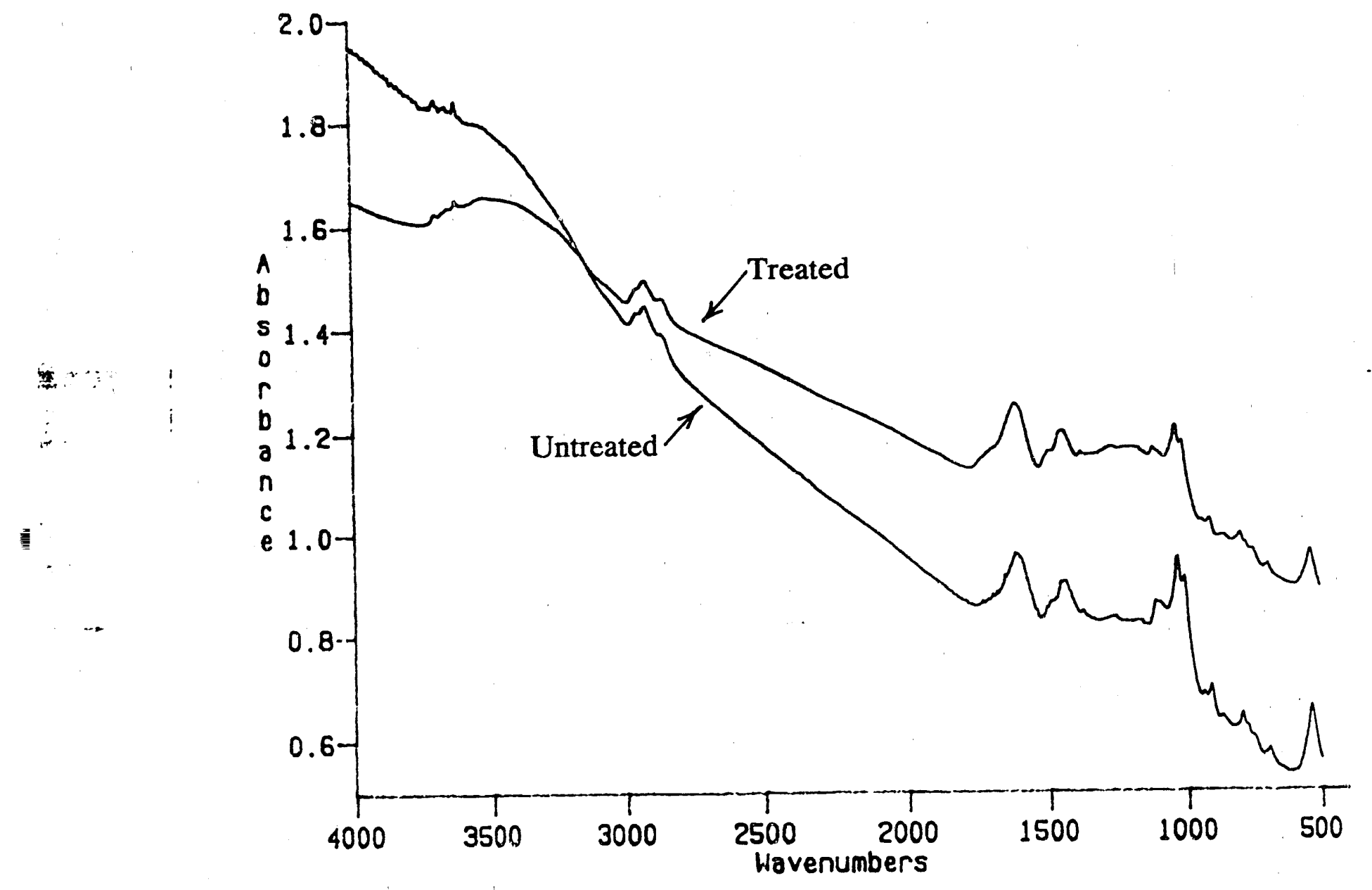

Figure 10 - FTIR Spectra of Untreated and Treated Illinois \#6 Coal 

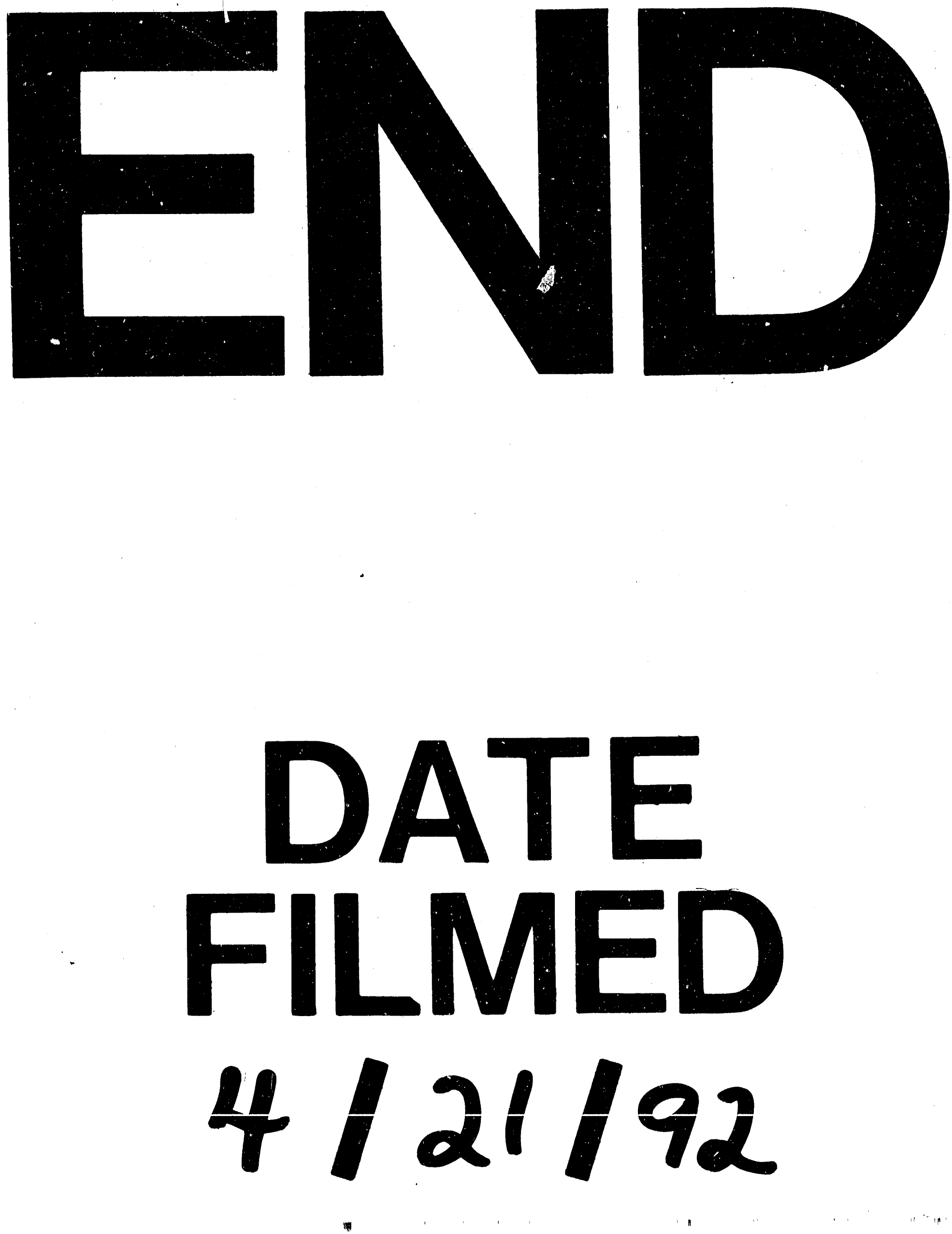
